Journal of Engineering and Applied Sciences 14 (17): 6533-6539, 2019

ISSN: 1816-949X

(C) Medwell Journals, 2019

\title{
Differential Model of the Financial Indicators of Passenger Carriers
}

\author{
${ }^{1}$ Alexander Martynenko, ${ }^{2}$ Sergey Vikharev and ${ }^{2}$ Maksim Liapustin \\ ${ }^{1}$ Ural State University of Railway Transport, Kolmogorova Street 66, 620034 Ekaterinburg, Russia \\ ${ }^{2}$ Ural Federal University, 19 Mira Street, 620002 Ekaterinburg, Russia
}

\begin{abstract}
The study is devoted to modeling of bus passenger carriers. Such companies are strictly regulated by regulatory authorities. Consequently, the financial performance of passenger carriers can change dramatically via. decisions of the regulator. Because of this, the adaptation of carriers to the requirements of the regulator is very important question. In this study, quite natural assumptions about the relationship between the main quantitative indicators of passenger carriers were formulated. This allowed us to derive a differential equation for the dynamics of the carriers profit under the conditions of constant external economic environment. For this equation, asymptotic estimates of the solutions and an estimate of the adaptation time carrier were obtained.
\end{abstract}

Key words: Transport system, passenger transportation, external economic environment, differential model, differential equation, asymptotic behavior

\section{INTRODUCTION}

The study is devoted to research and modeling of companies, carrying out urban and suburban bus transportation (such companies will be called carriers) Immediately it should be noted that the characteristic the passenger bus market is heavily regulated by the various state and municipal authorities (will call them the regulator) which is dictated by the need to provide an acceptable level of security, comfort and accessibility of public transport. Satisfaction of the existing demand in the society for the formation of a comfortable and safe living environment leads to the emergence of numerous requirements for the activities of carriers and as a consequence to an increase in their costs. On the other hand, it is important for the regulator to create a sustainable market for passenger transport and for this it is necessary to take steps to support carriers and create conditions that would help them adapt to rising costs. Carriers costs are also significantly affected by time-varying market factors which raises a natural and important question for the regulator about how the carrier adapts to the changing conditions of the external economic environment. The question of the relationship between the regulator, carriers and passengers was studied by Alexander Vasilyevich et al. (2009). In this study, the researchers based on the concept of a system with shared interests. Consider set of regulators-A (authorities) the set of Executors-E (executers) and the set of Consumers-C (customer). The $2^{\mathrm{x}}$ is the set of all subsets of an arbitrary set X (Boolean of X). The set of real numbers is traditionally denoted by $\mathrm{R}$. A system with shared interests is a collection (A, E, C, $\alpha, \gamma, \tau)$ where $\delta$ : $\mathrm{A} \times 2^{\mathrm{E}} \rightarrow \mathrm{R}, \gamma: \mathrm{E} \times 2^{\mathrm{C}} \rightarrow \mathrm{R}, \tau: \mathrm{A} \times 2^{\mathrm{C}} \rightarrow \mathrm{R}$ are the functions of interaction.

A natural example of systems with shared interests is the system of transport services for the population where $\mathrm{A}$ is a set of state and municipal authorities regulating the provision of transport services and allocating subsidies for their provision, $\mathrm{E}$ is a set of transport companies, $\mathrm{C}$ is a set of passengers. In systems with shared interests, the tasks of determining the necessary amount of funding and the strictness of regulation of the industry are set. That is the question arises concerning the determination of the functions of interaction which was studied by Say et al. (2011), Vikharev (2013a, b) and Vikharev (2014).

The main purpose of the research is to propose a dynamic differential model of interaction between the executor (carrier) and the external economic environment (largely determined by the regulator) which can be used to quantify the reaction (adaptation) of carriers to changes in regulation. The proposed model allows to set the interaction $\delta$ and thus, complements the results of (Vikharev et al., 2017) which investigated the impact on the profitability of carriers introduced by the regulator rules and regulations for the provision of transport services.

For further discussion, it is necessary to briefly describe the main features of the activities of carriers. Carriers in most cases are sole traders and their

Corresponding Author: Alexander Martynenko, Ural State University of Railway Transport, Kolmogorova Street 66 , 620034 Ekaterinburg, Russia 
management is carried out directly by the owners. The number of buses used by one carrier can reach several dozen. The carrier's revenue is generated from the cash proceeds from the sale of tickets to passengers. At the same time, the carrier has practically no possibility to influence the amount of these revenues, since, the fare, the schedule of movement along the route, the capacity of buses and a number of other parameters are strictly regulated by the regulator. Therefore, the increase in the carrier's profitability is possible mainly due to the reduction of costs which is carried out by improving existing and introducing new administrative mechanisms using more high-tech (cost-effective) methods of maintenance and repair of rolling stock, careful planning of its own activities and forecasting the situation in the transportation market. At the same time, we emphasize once again that a significant part of the carrier's costs are costs that are directly or indirectly caused by the actions of the regulator. In particular, the regulator directly formulates requirements for the safety and comfort of passengers which imposes additional requirements on both the rolling stock and its employees. Naturally, the implementation of such requirements is associated with increased costs. Indirect influence of the regulator is manifested, for example, in its monetary policy which affects the costs of the carrier through taxation and the amount of the interest rate on loans. It is important to note that the actions of the regulator can lead to a reduction in the costs of the carrier. For example, the regulator may take actions aimed at reducing fuel prices.

Basic notation and assumptions: The determining factor of the carrier's activities is Managerial Work (MW) which is carried out by the manager-entrepreneur (usually the owner) for a small carrier or a team of managers for a larger transport enterprise. All other factors (organizational structure of the enterprise, remuneration, costs for the purchase and maintenance of rolling stock, etc.) can take any value from a certain constant set and the optimal choice of such a value depends on the amount of MW spent on it.

The main idea of the approach proposed below is as follows. Consider MW as a limited resource that is used to Control the Operation (CO) and to Control the Development (CD). At the same time, $\mathrm{CO}$ means the management of the current activities of the enterprise and CD means activities aimed at changing the enterprise itself which allows it to adapt to the actions of the regulator (for more information about $\mathrm{CO}$ and $\mathrm{CD}$ see for example (Verhoglazenko, 2012). If the criterion of MW distribution is known then the dynamics of the company's financial indicators will be determined by the optimal MW distribution between $\mathrm{CO}$ and $\mathrm{CD}$.
Turning to the formalization of the carrier, we consider the following notation: $Q(t)$ is the intensity of $\mathrm{MW} ; \mathrm{r}(\mathrm{t})$ is the intensity of MW spent on $\mathrm{CO}, \mathrm{q}(\mathrm{t})$ is the intensity of MW spent on CD. Under the intensity of the $\mathrm{MW}$ is the number of MW spent per unit of time for example per 1 working day. It is assumed that $\mathrm{r}(\mathrm{t})$ and $\mathrm{q}(\mathrm{t})$ are non-negative, $\mathrm{Q}(\mathrm{t})=\mathrm{Q}$ const:

$$
\forall \mathrm{t} \geq 0 \mathrm{r}(\mathrm{t})+\mathrm{q}(\mathrm{t})=\mathrm{Q}
$$

Where:

$$
\begin{aligned}
\mathrm{Q} & =\text { The performance of } \mathrm{MW} \\
\mathrm{r}(\mathrm{t}) \text { and } \mathrm{q}(\mathrm{t})= & \text { The performance of } \mathrm{CO} \text { and } \mathrm{CD}, \\
& \text { respectively }
\end{aligned}
$$

The carrier is considered as a system that can be in different states from a certain set of states $\Omega$. For any time $\mathrm{t}_{1}<\mathrm{t}_{2}$ the state of the system $\omega\left(\mathrm{t}_{2}\right) \in \Omega$ is uniquely determined by the state of the system $\omega\left(\mathrm{t}_{1}\right) \epsilon \Omega$ and the values of $q(\tau)$ for $\tau \epsilon\left(t_{1}, t_{2}\right)$. Let $P(t)$ denote the carrier's profit intensity, i.e., carrier's profit per unit of time and suppose that at any moment of time $t$, the value of $\mathrm{P}(\mathrm{t})$ depends on $r(t)$ and $\omega(t)$, i.e., $P(t)=P(r(t), \omega(t))$.

The activity of individual buses of one carrier is carried out quite independently, therefore, it can be assumed that while other conditions are preserved, the carrier's profit and MW costs on the CO will be proportional to the number of buses. This gives grounds for assuming that the intensity of profit $\mathrm{P}(\mathrm{t})$ is proportional to the performance of the $\mathrm{CO} r(\mathrm{t})$, i.e.

$$
\mathrm{P}(\mathrm{t})=\mathrm{P}(\mathrm{r}(\mathrm{t}), \omega(\mathrm{t}))=\gamma(\omega(\mathrm{t})) \mathrm{r}(\mathrm{t})
$$

Linearity will be violated for large and small values of $r(t)$ but at $r(t)$ close to real values $\gamma(t)=$ const $>0$, $\mathrm{v}(\mathrm{t})=\mathrm{p}(\omega(\mathrm{t}))$ and $\mathrm{p}: \Omega \rightarrow \mathrm{R}$. Also assume that the map $\mathrm{p}$ is bounded and denote $c=\sup _{\omega \in \Omega} \mathrm{p}(\omega)$. Let $\mathrm{b}$ be the carrier's revenue at any time $t$ (it was noted above that the carrier does not affect its size). The following symbols are introduced: $\mathrm{a}=\mathrm{b}-\mathrm{c}$ and $\mathrm{w}(\mathrm{t})=\mathrm{c}-\mathrm{v}(\mathrm{t})$. Take into account that $\gamma=\mathrm{Q}-1$ and then from Eq. 2 it follows that:

$$
\mathrm{P}(\mathrm{Q}, \omega(\mathrm{t}))=\gamma \mathrm{Qv}(\mathrm{t})=\mathrm{v}(\mathrm{t})
$$

i.e., $v(t)$ carrier's profit, provided that at any time the performance of $\mathrm{CO}$ is equal to $\mathrm{Q}$. Accordingly, $\mathrm{a}(\mathrm{t})$ the minimum possible costs of the carrier and $\mathrm{w}(\mathrm{t})$ lost profit (the result of the "imperfection" of the carrier) provided that at any time the performance of $\mathrm{CO}$ is equal to $\mathrm{Q}$.

Let us now consider the activities of the carrier for a period of time $(t, t+\Delta t)$. By virtue of the above assumptions, $\omega(\mathrm{t}+\Delta \mathrm{t})$ is uniquely determined by the state $\omega(\mathrm{t})$ and the values $\mathrm{q}(\tau)$ at $\tau \in(\mathrm{t}, \mathrm{t}+\Delta \mathrm{t})$. It is assumed that $\mathrm{v}(\mathrm{t}+\Delta \mathrm{t})$ is uniquely determined by the values $\mathrm{v}(\mathrm{t})$ and $\mathrm{q}(\tau)$ 
at $\tau \epsilon(t, t+\Delta t)$. Regarding the nature of this dependence an assumption is considered that with a small $\Delta \mathrm{t}$ :

$$
\mathrm{w}(\mathrm{t}+\Delta \mathrm{t})=(1-\mu(\mathrm{q}(\mathrm{t})))^{\Delta \mathrm{t}} \mathrm{w}(\mathrm{t})
$$

where, $\mu(q)=q /(\alpha+q), \quad \alpha>0$. The naturalness of assumption Eq. 3 is the result of the following heuristic considerations. It is considered that under the action of the $C D, v$ changes discretely at times $\mathrm{k}=0,1, \ldots, \mathrm{n}$ and the magnitude of the change at each step is proportional to the missed profit $\mathrm{w}$ (the greater the unearned but possible profit, the more opportunities there are for the development of the enterprise in order to make it), i.e.,

$$
\mathrm{v}(\mathrm{k}+1)-\mathrm{v}(\mathrm{k})=\gamma(\mathrm{q}(\mathrm{k})) \mathrm{w}(\mathrm{k})
$$

where, $\gamma(q)$ is a dimensionless quantity defined at $q \geq$. It is obvious that $\gamma(q)$ must be continuous, positive increasing and convex upward throughout its domain of definition and the following conditions must be met for it:

$$
\gamma(0)=0 \text { and } \lim _{q \rightarrow \infty} \gamma(q)=1
$$

Such requirements on $\gamma(q)$ define a wide class of functions. One of the simplest representatives of this class is the one-parameter family of functions $\mu(q)$. Note that the parameter $\alpha$ has a fairly simple interpretation. whereas:

$$
\max _{q \geq 0} \frac{\partial}{\partial q}(\mu(q) w)=\max _{q \geq 0} \frac{\alpha}{(q+\alpha)^{2}} w=\frac{1}{\alpha} w
$$

Then the value $\mathrm{A}=1 / \alpha$ represents the maximum possible return on the costs of $M W$ for $C D$, i.e. $A$ characterizes the "ability" of a company to change qualitatively at MW costs for $\mathrm{CD}$. Given the choice of $\gamma$ (q) $=\mu$ (q) from Eq. 4 follows:

$$
\mathrm{w}(\mathrm{k}+1)=(1-\mu(\mathrm{q}(\mathrm{k})) \mathrm{w}(\mathrm{k})
$$

It follows that:

$$
\mathrm{w}(\mathrm{n})=\prod_{\mathrm{k}=1}^{\mathrm{n}}(1-\mu(\mathrm{q}(\mathrm{k})) \mathrm{w}(0)
$$

And if $\mathrm{q}(\mathrm{k})=\mathrm{q}$ does not depend on $\mathrm{k}$ then:

$$
\mathrm{w}(\mathrm{n})=(1-\mu(\mathrm{q}))^{\mathrm{n}} \mathrm{w}(0)
$$

Since, with sufficiently small $\Delta t$ we can assum $(\tau)=q(t)$ at $\tau \epsilon(t, t+\Delta t)$ then relation Eq. 5 makes the assumption Eq. 3 natural. From Eq. 3 receive:

$$
\begin{aligned}
& \Delta \mathrm{v}=\mathrm{v}(\mathrm{t}+\Delta \mathrm{t})-\mathrm{v}(\mathrm{t})=-(\mathrm{w}(\mathrm{t}+\Delta \mathrm{t})-\mathrm{w}(\mathrm{t}))= \\
& \left(-(1-\mu(\mathrm{q}(\mathrm{t})))^{\Delta t}\right) \mathrm{w}(\mathrm{t})
\end{aligned}
$$

Thus, MW costs for CD over time $(\mathrm{t}, \mathrm{t}+\Delta \mathrm{t})$ provide an increase in profits by:

$$
\mathrm{T} \Delta v=\mathrm{T}\left(1-(1-\mu(\mathrm{q}(\mathrm{t})))^{\Delta \mathrm{t}}\right) \mathrm{w}(\mathrm{t})
$$

for a period of time $\tau \epsilon(t+\Delta t, t+\Delta t+T)$. We emphasize that the profit will increase by the value Eq. 7 only under the condition that the $\mathrm{CO}$ performance will be equal to $\mathrm{Q}$ (see above interpretation $\mathrm{v}(\mathrm{t}))$ those provided that $\forall \tau \epsilon(\mathrm{t}+\Delta \mathrm{t}$, $\mathrm{t}+\Delta \mathrm{t}+\mathrm{T})$ done $\gamma(\mathrm{t})=\mathrm{Q}$.

On the other hand from the fact that with sufficiently small $\Delta \mathrm{t}$ will $\gamma(\tau)=\mathrm{Q}-\mathrm{q}(\tau)=(\mathrm{t})$ for $\tau \epsilon(\mathrm{t}, \mathrm{t}+\Delta \mathrm{t})$ and assumptions (2) imply that $\mathrm{MW}$ costs on $\mathrm{CO}$ over time $(\mathrm{t}, \mathrm{t}+\Delta \mathrm{t})$ provide profit:

$$
\int_{t}^{t+\Delta t} P(\tau) d \tau=\frac{Q-q(\tau)}{Q} \int_{t}^{t+\Delta t} v(\tau) d \tau
$$

Finally, suppose that the carrier distributes the MW between the $\mathrm{CO}$ and the $\mathrm{CD}$ in order to maximize the amount of profit Eq. 7 expected from the MW costs for the $\mathrm{CD}$ and the profit Eq. 8 received from the MW costs for the $\mathrm{CO}$ those. So that, for a given $\mathrm{T}>0$ at any time $\mathrm{t}$ with a sufficiently small $\Delta$ maximize the value:

$$
\varphi(q)=T\left(1-(1-\mu(q(t)))^{\Delta t}\right) w(t)+\frac{Q-q}{Q} \int_{t}^{t+\Delta t} v(\tau) d \tau(9)
$$

The value of $\mathrm{T}$, appearing in this expression is a planning horizon, the time during which the carrier expects to carry out its activities. Its value depends on the stability of the external economic environment and the predictability of the actions of the regulator. We assume that the quantities $\mathrm{Q}, \mathrm{T}, \alpha, \mathrm{b}$, a are given and consider the problem of finding the function $v(t)$ provided that all the assumptions made above are fulfilled.

Derivation of the differential equation: Find the largest value of the function Eq. 9 on the interval $(0, Q)$ for this calculate the derivative:

$$
\frac{\mathrm{d} \varphi}{\mathrm{dq}}=\frac{\Delta \mathrm{t} \cdot \alpha^{\Delta t} \cdot \mathrm{w}(\mathrm{t}) \cdot \mathrm{T}}{(\mathrm{q}+\alpha)^{\Delta \mathrm{t}+1}}-\frac{1}{\mathrm{Q}} \int_{\mathrm{t}}^{\mathrm{t}+\Delta \mathrm{t}} \mathrm{v}(\tau) \mathrm{d} \tau
$$


Elementary calculations show that the equation:

$$
\frac{\mathrm{d} \varphi}{\mathrm{dq}}=0
$$

Has a single solution:

$$
\mathrm{q}_{0}=\mathrm{q}_{0}(\Delta \mathrm{t})=\left(\frac{\mathrm{Q} \cdot \alpha^{\Delta \mathrm{t}} \cdot \mathrm{w}(\mathrm{t}) \cdot \mathrm{T}}{\frac{1}{\Delta \mathrm{t}} \int_{\mathrm{t}}^{\mathrm{t}+\Delta \mathrm{t}} \mathrm{v}(\tau) \mathrm{d} \tau}\right)^{\frac{1}{\Delta t+1}}-\alpha
$$

It is easy to see that the condition:

$$
\frac{\mathrm{Q}}{\alpha}>\frac{\frac{1}{\Delta \mathrm{t}} \int_{\mathrm{t}}^{\mathrm{t}+\Delta t} \mathrm{v}(\tau) \mathrm{d} \tau}{\mathrm{w}(\mathrm{t}) \cdot \mathrm{T}}
$$

Is equivalent to each of the following two inequalities:

$$
\frac{\mathrm{d} \varphi}{\mathrm{dq}}(0)>0 \text { and } \mathrm{q}_{0}(\Delta \mathrm{t})>0
$$

Similarly, the condition:

$$
\frac{\mathrm{Q}}{(\mathrm{Q}+\alpha)^{1+\Delta t}}<\frac{\frac{1}{\Delta t} \int_{\mathrm{t}}^{\mathrm{t}+\Delta t} \mathrm{v}(\tau) \mathrm{d} \tau}{\alpha^{\Delta t} \cdot \mathrm{w}(\mathrm{t}) \cdot \mathrm{T}}
$$

Is equivalent to each of the following 2 inequalities:

$$
\frac{\mathrm{d} \varphi}{\mathrm{dq}}(\mathrm{Q})<0 \text { and } \mathrm{q}_{0}(\Delta \mathrm{t})<\mathrm{Q}
$$

Note that the conditions Eq. 11 and 13 are consistent because the inequality:

$$
\frac{\mathrm{Q}}{(\mathrm{Q}+\alpha)^{1+\Delta t}}<\frac{\mathrm{Q}}{\alpha^{1+\Delta t}}
$$

performed on all $\mathrm{Q}, \alpha>0$. Thus, if the conditions Eq. 11 and 13 are met, obtain $q_{0} \in(0, Q)$ and on $\operatorname{segment}(0, Q)$ function $\varphi$ (q) function takes its greatest value at the point $\mathrm{q}_{0}$.

The obtained restrictions Eq. 11 and 13 are caused by the fact that in the sense of the problem the values of the variable q must belong to the segment $(0, Q)$. However, it is easy to verify that regardless of the conditions Eq. 11 and 13 at the point $q_{0}$ function $\varphi(q)$ reaches its highest value on the set $(-\alpha,+\infty)$. Indeed, $\mathrm{q}_{0}$ the only critical point of the function $\varphi(q)$ and it belongs to the set under consideration $(-\alpha,+\infty)$ at the ends of which the relations are performed:

$$
\lim _{q \rightarrow \alpha+0} \frac{d \varphi}{d q}(q)=+\infty \text { and } \lim _{q \rightarrow+\infty} \frac{d \varphi}{d q}(q)=-\frac{1}{Q} \int_{t}^{t+\Delta t} v(\tau) d \tau<0
$$

Therefore, if $\mathrm{CO}$ performance can make sense in cases where it is negative and when it is greater than $Q$, the optimal distribution of $\mathrm{MW}$ performance between $\mathrm{CO}$ and $\mathrm{CD}$ will continue to be achieved when $\mathrm{q}=\mathrm{q}_{0}$. Choosing as $q$ the value of $q_{0}(\Delta t)$ from the relation (6) receive:

$$
\frac{\mathrm{w}(\mathrm{t}+\Delta \mathrm{t})-\mathrm{w}(\mathrm{t})}{\Delta \mathrm{t}}=\frac{\left(1-\mu\left(\mathrm{q}_{0}(\Delta \mathrm{t})\right)\right)^{\Delta \mathrm{t}}-1}{\Delta \mathrm{t}} \mathrm{w}(\mathrm{t})
$$

To go to the limit at $\Delta \mathrm{t} \rightarrow 0$ in equality Eq. 15 use relations:

$$
\lim _{\Delta t \rightarrow 0} \frac{1}{\Delta t} \int_{t}^{t+\Delta t} v(\tau) d \tau=v(\tau) \text { and } \lim _{\Delta t \rightarrow 0} \frac{x^{\Delta t}-1}{\Delta t}=\operatorname{In} x
$$

Then for $\mathrm{q}_{0}(\Delta \mathrm{t})$ receive:

$$
\tilde{q}=\lim _{\Delta t \rightarrow 0} \mathrm{q}_{0}(\Delta \mathrm{t})=\mathrm{QT} \frac{\mathrm{w}(\mathrm{t})}{\mathrm{v}(\mathrm{t})}-\alpha
$$

Moving to the limit in the ratio Eq. 15 and using the above designation $\mathrm{A}=1 / \alpha$, receive the differential equation:

$$
\frac{d w}{d t}=w(t) \operatorname{In} \frac{v(t)}{\operatorname{AQTw}(t)}
$$

Introducing the notation $=(\mathrm{AQT})^{-1}$ write the equation as:

$$
\mathrm{w}^{\prime}=\mathrm{w} \operatorname{In} \frac{\mathrm{M}(\mathrm{c}-\mathrm{w})}{\mathrm{w}}
$$

\section{MATERIALS AND METHODS}

Research equation: It is easy to check that for any $\mathrm{w} \epsilon(0, \mathrm{c})$ there is a neighborhood in which the right side of the Eq. 16 satisfies the Lipschitz condition. Therefore, the Cauchy problem for the Eq. 16 with initial condition $\mathrm{w}\left(\mathrm{t}_{0}\right)=\mathrm{w}_{0}$ has the only solution when $\mathrm{t}_{0} \geq 0$ and $0<\mathrm{W}_{0}<\mathrm{c}$ and this decision will be determined for all $\mathrm{t}_{\mathrm{a}}<0$. Also note that the equation in question is autonomous (therefore, integrable in quadratures) and its stationary solution is:

$$
\mathrm{w}^{*}=\frac{\mathrm{Mc}}{\mathrm{M}+1}
$$


The properties of the solutions of the equation that are important for further are formulated as the following theorem.

Theorem 1: Let be $\mathrm{w}_{0} \in(0, c)$ and $\mathrm{w}(\mathrm{t})$ solution of the cauchy problem for Eq. 16 with initial condition $\mathrm{w}(0)=\mathrm{w}_{0}$. Then the following statements are true. If $\mathrm{w}_{0}>\mathrm{w}^{*}$ that $w(t)$ strictly decreases for all $t \geq 0$ and:

$$
\forall \mathrm{t} \geq 0 \quad \mathrm{w}^{*} \leq \mathrm{w}(\mathrm{t}) \leq \mathrm{w}^{*}+\left(\mathrm{w}_{0}-\mathrm{w}^{*}\right) \mathrm{e}^{-(\mathrm{M}+1) \mathrm{t}}
$$

If $\mathrm{w}_{0}>\mathrm{w}^{*}$ that $\mathrm{w}(\mathrm{t})$ strictly decreases for all $\mathrm{t} \geq 0$ and:

$$
\forall \mathrm{t} \geq 0 \quad \mathrm{w}^{*} \geq \mathrm{W}(\mathrm{t}) \geq \mathrm{w}^{*}-\left(\mathrm{w}_{0}-\mathrm{w}^{*}\right) \mathrm{e}^{\Lambda \mathrm{t}}
$$

Where:

$$
\Lambda=\frac{\mathrm{w}_{0} \operatorname{In} \frac{\mathrm{M}\left(\mathrm{c}-\mathrm{w}_{0}\right)}{\mathrm{w}_{0}}}{\mathrm{w}^{*}-\mathrm{w}_{0}}
$$

Evidence. If $\mathrm{w}_{0}>\mathrm{w}^{*}$ then due to the uniqueness of the solution of the Cauchy problem for any $\mathrm{t}_{0}=0$ and $0<\mathrm{w}_{0}<\mathrm{c}$ will be fair $\mathrm{w}(\mathrm{t})>\mathrm{w}^{*}$ at $\mathrm{t} \geq 0$. Then receive:

$$
\mathrm{w}^{\prime}(\mathrm{t})=\mathrm{w}(\mathrm{t}) \operatorname{In} \frac{\mathrm{M}(\mathrm{c}-\mathrm{w}(\mathrm{t}))}{\mathrm{w}(\mathrm{t})}<\mathrm{w}(\mathrm{t}) \operatorname{In} \frac{\mathrm{M}\left(\mathrm{c}-\mathrm{w}^{*}\right)}{\mathrm{w}^{*}}=0
$$

Therefore, $w(t)$ strictly decreases for all $t \geq 0$. Similarly, at $\mathrm{w}_{0}<\mathrm{w}^{*}$ will be fair $\mathrm{w}(\mathrm{t})<\mathrm{w}^{*}$ for $\mathrm{t} \geq 0$ and:

$$
w^{\prime}(t)=w(t) \operatorname{In} \frac{M(c-w(t))}{w(t)}>w(t) \operatorname{In} \frac{M\left(c-w^{*}\right)}{w^{*}}=0
$$

Means, $w(t)$ strictly decreases for all $t \geq 0$. Let be $n \in N$ and $\mathrm{k}=\overline{0, \mathrm{n}}$ for arbitrary $\mathrm{t} \geq 0$ consider the sequence $\mathrm{t}_{\mathrm{n}, \mathrm{k}}=$ $\mathrm{kt} / \mathrm{n}$ and integrate Eq. 16 over the interval $\left(\mathrm{t}_{\mathrm{n}, \mathrm{k}}, \mathrm{t}_{\mathrm{n}, \mathrm{k}+1}\right)$ :

$$
\mathrm{w}\left(\mathrm{t}_{\mathrm{n}, \mathrm{k}+1}\right)=\mathrm{w}\left(\mathrm{t}_{\mathrm{n}, \mathrm{k}}\right)+\int_{\mathrm{t}_{\mathrm{n}, \mathrm{k}}}^{\mathrm{t}_{\mathrm{n}, \mathrm{k}+\mathrm{l}}} \mathrm{w}(\mathrm{t}) \operatorname{In} \frac{\mathrm{M}(\mathrm{c}-\mathrm{w}(\mathrm{t}))}{\mathrm{w}(\mathrm{t})} \mathrm{dt}
$$

Let us show the validity of the estimate Eq. 17 in the case $\mathrm{w}_{0}>\mathrm{w}^{*}$. As with any $\mathrm{x}>0$ fair inequality $\ln \mathrm{x}<\mathrm{x}-1$ then from Eq.19 receive:

$$
\mathrm{w}\left(\mathrm{t}_{\mathrm{n}, \mathrm{k}+1}\right) \leq \mathrm{w}\left(\mathrm{t}_{\mathrm{n}, \mathrm{k}}\right)+\int_{\mathrm{t}_{\mathrm{n}, \mathrm{k}}}^{\mathrm{t}_{\mathrm{n}, \mathrm{k}+1}}(\mathrm{Mc}-(\mathrm{M}+1) \mathrm{w}(\mathrm{t})) \mathrm{dt}
$$

Subtracting $\mathrm{w}^{*}$ from both sides of this inequality and and considering that $\mathrm{w}(\mathrm{t})$ decreases come to inequality:

$$
\begin{aligned}
& w\left(t_{n, k+1}\right)-w^{*} \leq w\left(t_{n, k}\right)-w^{*}+\left(M c-(M+1) w\left(t_{n, k+1}\right)\right) \\
& \left(t_{n, k+1}-t_{n, k}\right) \leq w\left(t_{n, k}\right)-w^{*}-(M+1)\left(w\left(t_{n, k+1}\right)-w^{*}\right) \frac{t}{n}
\end{aligned}
$$

Consequently:

$$
\mathrm{w}\left(\mathrm{t}_{\mathrm{n}, \mathrm{k}+1}\right)-\mathrm{w}^{*} \leq \frac{\mathrm{w}\left(\mathrm{t}_{\mathrm{n}, \mathrm{k}}\right)-\mathrm{w}^{*}}{1+\frac{(\mathrm{M}+1)}{\mathrm{n}}}
$$

The consistent application of inequality Eq. 20 for any $n \in \mathbb{N}$ gives:

$$
\begin{aligned}
& \mathrm{w}(\mathrm{t})-\mathrm{w}^{*}=\mathrm{w}\left(\mathrm{t}_{\mathrm{n}, \mathrm{n}}\right)-\mathrm{w}^{*} \leq \frac{\mathrm{w}\left(\mathrm{t}_{\mathrm{n}, \mathrm{n}-1}\right)-\mathrm{w}^{*}}{1+\frac{(\mathrm{M}+1)}{\mathrm{n}}} \leq \\
& \frac{\mathrm{w}\left(\mathrm{t}_{\mathrm{n}, 0}\right)-\mathrm{w}^{*}}{\left(1+\frac{(\mathrm{M}+1) \mathrm{t}}{\mathrm{n}}\right)^{\mathrm{n}}} \leq \frac{\mathrm{w}_{0}-\mathrm{w}^{*}}{\left(1+\frac{(\mathrm{M}+1) \mathrm{t}}{\mathrm{n}}\right)^{\mathrm{n}}}
\end{aligned}
$$

Hence, we obtain the estimate Eq. 17 after passing to the limit at $n \rightarrow \infty$. We now show the validity of the estimate Eq. 18 in the case $\mathrm{w}_{0}<\mathrm{w}^{*}$. It is easy to check that for any $\lambda>0$ at $x \in\left(1, \mathrm{e}^{\lambda}\right)$ fair inequality:

$$
\text { In } x \geq \frac{\lambda}{\mathrm{e}^{\lambda}-1}(\mathrm{x}-1)
$$

Because inequality $\mathrm{w}_{0} \leq \mathrm{w}<\mathrm{w}^{*}$ tantamount to inequality:

$$
1<\frac{\mathrm{M}(\mathrm{c}-\mathrm{w})}{\mathrm{w}} \leq \mathrm{e}^{\lambda}
$$

At:

$$
\lambda=\operatorname{In} \frac{\mathrm{M}\left(\mathrm{c}-\mathrm{w}_{0}\right)}{\mathrm{w}_{0}}
$$

Then applying Eq. 22 to 19 receive:

$$
w\left(t_{n, k+1}\right) \geq w\left(t_{n, k}\right)+\int_{t_{n, k}}^{t_{n, k+1}} \frac{\lambda}{e^{\lambda}-1}(M c-(M+1) w(t)) d t
$$

Given that $\mathrm{w}(\mathrm{t})$ increases at $\mathrm{w}_{0}<\mathrm{w}^{*}$ from the last inequality follows:

$$
\begin{aligned}
& \mathrm{w}^{*}-\mathrm{w}\left(\mathrm{t}_{\mathrm{n}, \mathrm{k}+1}\right) \leq \mathrm{w}^{*}-\mathrm{w}\left(\mathrm{t}_{\mathrm{n}, \mathrm{k}}\right)-\frac{\lambda}{\mathrm{e}^{\lambda}-1}\left(\operatorname{Mc}-(\mathrm{M}+1) \mathrm{w}\left(\mathrm{t}_{\mathrm{n}, \mathrm{k}+1}\right)\right) \\
& \left(\mathrm{t}_{\mathrm{n}, \mathrm{k}+1}-\mathrm{t}_{\mathrm{n}, \mathrm{k}}\right) \leq \mathrm{w}^{*}-\mathrm{w}\left(\mathrm{t}_{\mathrm{n}, \mathrm{k}}\right)-\Lambda\left(\mathrm{w}^{*}-\mathrm{w}\left(\mathrm{t}_{\mathrm{n}, \mathrm{k}+1}\right)\right) \frac{\mathrm{kt}}{\mathrm{n}}
\end{aligned}
$$


Insofar as:

$$
\frac{\lambda}{\mathrm{e}^{\lambda}-1}(\mathrm{M}+1)=\Lambda
$$

Then:

$$
w\left(t_{n, k+1}\right)-w^{*} \leq \frac{w\left(t_{n, k}\right)-w^{*}}{1+\frac{\Lambda t}{n}}
$$

And arguing further as in Eq. 21 we obtain the estimate Eq. 18. In addition to the proved properties of the solutions of Eq. 16, we note that:

$$
\begin{aligned}
& w_{t t}^{\prime \prime}=\left(w \operatorname{In} \frac{M(c-w)}{w}\right)_{w}^{\prime} w_{t}^{\prime}= \\
& \left(\operatorname{In} \frac{M(c-w)}{w}-\frac{c}{c-w}\right) w_{t}^{\prime}=f(w) w_{t}^{\prime}
\end{aligned}
$$

And $\mathrm{f}(\mathrm{w})$ decreases at $\mathrm{w} \epsilon(0, \mathrm{c})$. Then at $\mathrm{w}_{0}>\mathrm{w}^{*}$ from inequality $\mathrm{w}(\mathrm{t})>\mathrm{w}^{*}$ and that $\mathrm{w}_{\mathrm{t}}^{\prime}(\mathrm{t})<0$ follows:

$$
w_{t t}^{\prime \prime}=f(w) w_{t}^{\prime}=-\frac{w_{t}^{\prime} c}{c-w}>0
$$

Therefore, at $\mathrm{w}_{0}>\mathrm{w}^{*}$ the solution of the Cauchy problem is convex down for all $t \geq 0$. Reasoning similarly, it can be shown that with $\mathrm{w}_{0}<\mathrm{w}^{*}$ and $\mathrm{f}\left(\mathrm{w}_{0}\right) \leq 0$ the solution of the Cauchy problem is convex upward $t \geq 0$. But if $w_{0}>0$ and $f\left(w_{0}\right)>0$ then the solution of the cauchy problem is convex downward $t \epsilon(0, \tilde{\mathrm{t}})$ and bulging up when $t \in(\tilde{\mathrm{t}}, \infty)$ where, $\tilde{\mathrm{t}}-$ solution (only) equation $\mathrm{f}(\mathrm{w}(\mathrm{t}))=0$. The integral curves obtained numerically under different initial conditions are shown in Fig. 1.

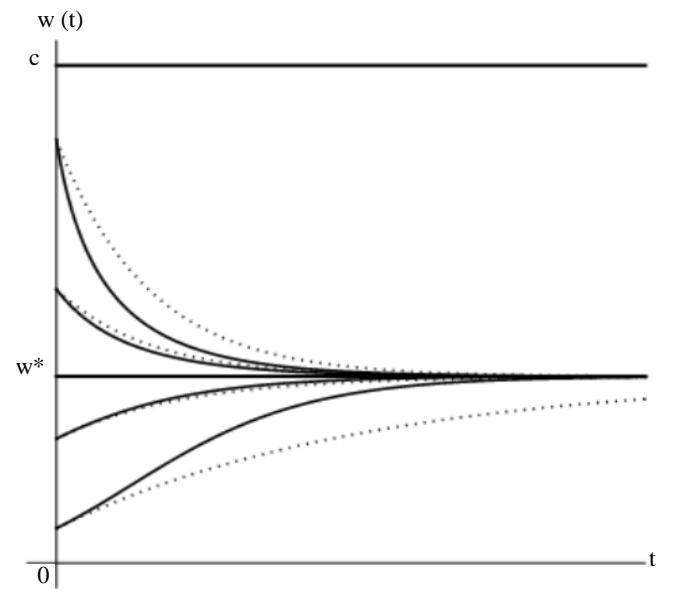

Fig. 1: Integral curves of Eq. 16. The dotted lines show the estimates Eq. 17 and 18

\section{RESULTS AND DISCUSSION}

Interpretation and use of the results: From estimates Eq. 17 and 18 receive:

$$
\lim _{\mathrm{t} \rightarrow \infty} \mathrm{v}(\mathrm{t})=\mathrm{v}^{*}=\mathrm{c}-\mathrm{w}^{*}=\frac{\mathrm{c}}{\mathrm{M}+1}=\frac{\operatorname{AQT}(\mathrm{b}-\mathrm{a})}{\operatorname{AQT}+1}
$$

Therefore, at $t \rightarrow \infty \mathrm{MV}$ costs for $\mathrm{CD}$ are:

$$
\begin{aligned}
& q(t)=\tilde{q}(t)=Q T \frac{w(t)}{c-w(t)}-\frac{1}{A}=\frac{A Q T+1}{A} \\
& \frac{w(t)-w^{*}}{c-w(t)}=\frac{A Q T+1}{A} \frac{v^{*}-v(t)}{v(t)} \rightarrow 0
\end{aligned}
$$

And profit:

$$
P(t)=\frac{Q-q(t)}{Q} v(t)=v(t)-\frac{A Q T+1}{A}\left(v^{*}-v(t)\right) \rightarrow v^{*}
$$

Thus, in the conditions of a constant external economic environment, the carrier "goes" to the marginal profit $\mathrm{v}^{*}$ and reduces to zero the costs of MT for CD for any initial value $\mathrm{w}_{0}$. It should be noted that the remaining properties of the solution $\mathrm{w}(\mathrm{t})$ receive a meaningful interpretation only in the most natural case $\mathrm{v}_{0}<\mathrm{v}^{*}$. If $\mathrm{v}_{0}>\mathrm{v}^{*}$ then this means that at the initial moment of time the profit exceeds the limit value and further it decreases due to the fact that $\mathrm{q}(\mathrm{t})<0$. Since, this situation is unrealistic and requires the interpretation of negative performance values, we will further consider only those solutions of Eq. 16 for which $\mathrm{v}_{0}<\mathrm{v}^{*}$.

The estimate Eq. 17 fairly accurately characterizes the speed with which the carrier's profit tends to $v^{*}$. The same estimate allows us to estimate the time for which the carrier's profit becomes arbitrarily close to $v^{*}$. Let be $\mathrm{w}(\mathrm{t})=\mathrm{c}-\mathrm{v}(\mathrm{t})$ solution of the cauchy problem for Eq. 16 with the initial condition $\mathrm{w}(0)=\mathrm{w} 0=\mathrm{c}-\mathrm{v} 0$. We pose the question of finding for any $\varepsilon>0$ that moment in time $\mathrm{T}_{\varepsilon}>0$ that:

$$
\forall \mathrm{t}>\mathrm{t \varepsilon v} \mathrm{v}^{*}-\mathrm{v}(\mathrm{t}) \leq \varepsilon \mathrm{v}^{*}
$$

From the estimate Eq. 17 it follows that:

$$
\mathrm{v}(\mathrm{t})=\mathrm{c}-\mathrm{w}(\mathrm{t})>\mathrm{v}^{*}-\left(\mathrm{v}^{*}-\mathrm{v}_{0}\right) \mathrm{e}^{-(\mathrm{M}+1) \mathrm{t}}
$$

Hence, inequality Eq. 23 will be satisfied if the inequality:

$$
\left(\mathrm{v}^{*}-\mathrm{v}_{0}\right) \mathrm{e}^{-(\mathrm{M}+1) \mathrm{t}} \leq \varepsilon \mathrm{v}^{*}
$$


Which in turn is tantamount to inequality $\mathrm{t} \geq \mathrm{t}_{\varepsilon}$ if put:

$$
\mathrm{t}_{\varepsilon}=\frac{1}{\mathrm{M}+1} \ln \frac{\mathrm{v}^{*}-\mathrm{v}_{0}}{\varepsilon \mathrm{v}^{*}}
$$

Similarly, we can consider the question of the speed and time of the carrier's adaptation to a sharp change in the external economic environment. Let be $\mathrm{w}_{1}(\mathrm{t})=\mathrm{c}_{1}-\mathrm{v}_{1}(\mathrm{t})$ solution of Eq. 16 at $c=c_{1}>0$. If at some time $t_{0}$ costs increase by $\mathrm{d}\left(0<\mathrm{d}<\mathrm{c}_{1}\right)$ then it is natural to use the Cauchy problem for the equation to describe the carrier's future activities Eq. 16 at $\mathrm{c}=\mathrm{c}_{2}=\mathrm{c}_{1}$-d with initial condition $\mathrm{v}\left(\mathrm{t}_{0}\right)=\mathrm{v}_{1}\left(\mathrm{t}_{0}\right)-\mathrm{d}$. Denoting the solution of this problem through $\mathrm{v}_{2}(\mathrm{t})$ from the estimate Eq. 17 receive:

$$
\mathrm{v}_{2}(\mathrm{t})>\mathrm{v}_{2}^{*}-\left(\mathrm{v}_{2}^{*}-\mathrm{v}_{1}\left(\mathrm{t}_{0}\right)+\mathrm{d}\right) \mathrm{e}^{-(\mathrm{M}+1) \mathrm{t}}
$$

Consequently:

$$
\forall \mathrm{t}>\mathrm{t}_{\varepsilon} \mathrm{v}_{2}^{*}-\mathrm{v}_{2}(\mathrm{t}) \leq \varepsilon \mathrm{v}_{2}^{*}
$$

Where $\mathrm{v}_{2}^{*}=\mathrm{c}_{2} /(\mathrm{M}+1)$ and:

$$
\mathrm{t}_{\varepsilon}=\frac{1}{\mathrm{M}+1} \operatorname{In} \frac{\mathrm{v}_{2}^{*}-\mathrm{v}_{1}\left(\mathrm{t}_{0}\right)+\mathrm{d}}{\varepsilon \mathrm{v}_{2}^{*}}
$$

\section{CONCLUSION}

The result obtained is important from the point of view of the implementation of state regulation of the activities of passenger carriers, since, it allows us to estimate the time required for the carrier to financially adapt to the requirements imposed by the regulator.

\section{ACKNOWLEDEGEMENT}

The researchers acknowledge the support from the Russian Science Foundation (Project No. 17-71-20108).

\section{REFERENCES}

Alexander Vasilyevich, S., S.V. Vikharev and S.V. Sizy, 2009. [Organizational processes in networks with divided interests: Relevance, problem statement, research plan (In Russian)]. Bull. Ural State Univ. Transport, 2: 34-42.

Say, V.M., S.V. Sizy, S.V. Vikharev and K.A. Varankina, 2011. [Organization of the maintenance of transport infrastructure in networks with divided interests using the mathematical theory of automata (In Russian)]. Bull. Ural State Univ. Commun., 3: 42-54.

Verhoglazenko, V.N., 2012. [Criterion Management of the Company: Monograph]. Infra-M Publishing House, Moscow, Russia,ISBN:978-5-16-005227-4,Pages: 206 (In Russian).

Vikharev, S., 2013a. Mathematical modeling of development and reconciling cooperation programs between natural monopoly and regional authorities. Appl. Math. Sci., 7: 5457-5462.

Vikharev, S., 2013b. Verification of mathematical model of development cooperation programs between natural monopoly and regional authorities. Appl. Math. Sci., 7: 5463-5468.

Vikharev, S., 2014. Computer modeling of sustainability and support of enterprises in organizational networks. Appl. Mathe. Sci., 8: 1239-1246.

Vikharev, S., D Mironov, D. Brusyanin and I. Nizovtseva, 2017. Modelling quality switching on public transport by discrete series of queuing systems in shared interests network. Proceedings of the 9th International Conference on Transport Problems, June 280-30, 2017, Katowice, Poland, pp: 87-93. 